Clóvis Veríssimo do Couto e Silva, catedrático de direito civil, é diretor da Faculdade de Direito da Universidade Federal do Rio Grande do Sul.

\title{
A Ordem jurídica e a economia
}

1. Embora contraditório, o art. 2 da Constituição de Portugal declara que "A República Portuguesa é um estado democrático baseado na soberania popular, no respeito e na garantia dos direitos e liberdades fundamentais e no pluralismo de expressão e organização política democrática" , mas conclui que tudo "tem por objetivo assegurar a transição para o socialismo criando as condições para o exercício democrático do poder pelas classes trabaIhadoras". O art. 1 afirma, in fine, que o Estado português "está dedicado a sua transformação numa sociedade sem classes." Como resultado desta decisão, várias disposiçōes tiveram resultados imediatos no plano econômico. Disposições como as do art. $10, n$ :2, sobre os principais meios de produção complementadas pelas disposiç̃es do art. 80 e seguintes, especialmente os artigos que tratam do 'plano' arts. 91 e 95 do modelo socialista de planejamento. Recebeu, no entanto, críticas do deputado Victor Moreira e mereceu resposta do representante socialista Carlos Lage que não considerava contraditórias as disposições dos artigos relacionados com a 'organização econômica' IVeja Caldeira Silva, Constituição Polftica da República Portuguesa de 1976, Lisboa, p. $610 \mathrm{ff}, 1976)$.
A relacão entre a ordem jurídica e a economia é sempre assunto de grande interesse. Hoje em dia, com os aspectos econômicos de nossos problemas excessivamente destacados, muitas vezes com sacrificio de uma solução justa, este tema oferece-nos a oportunidade de lançar os olhos sobre algumas das principais orientações econômicas e, acima de tudo, sobre sua relação com a ordem jurídica. É importante observar de que modo a Constituição, comolei suprema, regula esta área de extrema importância, precisamente porque adotamos o sistema de uma constituição escrita, de inspiração americana, como defendido por Hamilton no The Federalist n: 78 , e aplicado pelo Presidente da Corte Suprema, Marshall no famoso processo Marbury versus Madison merecem também menção os vários meios de controle da economia, sejam, mesmo, os referentes aos contratos obrigatórios ou cogentes. Estes revelam diferentes escalas reguladoras do mercado muito embora, em se tratando de um regime de economia mista, geralmente preservem intacto o mercado. O mercado é entendido não como uma entidade estática diante do Estado mas como um processo de cuja dinamização, por vezes, o próprio Estado participa.

\section{A Influência recíproca da economia e do direito}

Existe, é claro, uma influência recíproca entre a economia e o direito. Embora seja inaceitável a tese de que a legislação é o resultado do desejo da classe dirigente, admite-se que certas situações econômicas orientem e induzam a adoção e defesa de certas idéias. Em sentido mais amplo, o relacionamento entre a economia e o direito depende de decisões políticas adotadas e transformadas em norma legal. Há, porém, às vezes, uma disparidade entre os princípios adotados e sua aplicação prática. Por este motivo, numa sociedade pluralista é sempre necessário que o Estado não se identifique com uma orientação ideológica ou com determinada teoria econômica. Por exemplo: observem o que ocorreu com a Constituição portuguesa em que foi adotada a fórmula socialista 1 . 
2. La proprietá nel sistema privatistico della Seconda Escolastica (A propriedade no sistema privatista da Segunda Escolástical em: La Seconda Escolastica nella formazione del diritto privato moderno (A Segunda Escolástica na formação do direito privado modernol Milão, 1973, p. 131.
Isto causou grandes dificuldades no funcionamento dos outros partidos que ou não tinham a mesma orientação ou mesmo a combatiam. Desta decisão política decorreram várias conseqüências em relação a outras disposições da Constituição, o que não parece adequado a um sistema democrático que requer uma pluralidade de partidos, reveladora da notável diversidade de tendências ideológicas e, conseqüentemente, econômicas. Temos aí o 'princípio da não-identificação' da Constituição com uma determinada doutrina, aceitando-se que cada um dos partidos vitoriosos possa implementar sua política econômica.

É sabido que esta solução nem sempre se coaduna com a realidade, por força de condições peculiares em cada país. No que concerne a economia existe, no entanto, uma reciprocidade entre estae o direito, embora não se possa dizer que o direito seja um resultado puro de fatos econômicos que a ele se referem. O direito não é a simples descrição ou admissão de fatos econômicos. Muito mais do que isso, o direito determina um comportamento baseado nos fatos. Freqüentemente o direito exerce um papel retificador no tocante a certos fatos. No entanto, não há dúvida de que as situações econômicas se refletem no direito. Por outra parte, conceitos jurídicos penetram as teorias econômicas na medida em que estas não visam somente à obtenção do maior lucro. Assim as soluções econômicas, para serem basicamente aceitas, devem refletir o conceito de justiça. Elas devem ser suscetíveis ao consentimento e não à imposição. Não é preciso recorrer à filosofia aristotélica para provar que a justiça distributiva, que preside o relacionamento entre o Estado e os indivíduos, está sujeita a princípios éticos claramente definidos. A superioridade da justiça comutativa, que é a justiça do indivíduo, sobre a distributiva é, ou parece ser, segundo afirmado por Paolo Grossi, não apenas o resultado da ética protestante mas um dos princípios fundamentais da doutrina da segunda escolástica, a escolástica de Molina, Lessius, Suarez e muitos outros ${ }^{2}$. Ela revela o surgimento do individualismo no direito antes mesmo da escola holandesa de Hugo Grotius. A tendência para que tudo permanecesse em mãos do particular, inclusive a própria economia, caracterizou um capitalismo de todo antiquado. Verificou-se que certas situações econômicas não permeneciam neutras perante a lei, mas se constituíam em aspecto importante para determinar a racionalização do povo e o seu papel na sociedade. Estas situações acabam por interferir no campo da regulamentação. Por outro lado, as ideologias econômicas, que abrangem uma extensa gama de discussões doutrinárias, quando transformadas em texto legal, se reduzem a uns poucos artigos. Este pequeno número de normas não cobre, de modo algum, todas as funções do Estado, tornando-se necessário usar elementos do Estado para uma melhor interpretação e aplicação destas normas e aqui aparecem todas as fontes secundárias do direito, a começar pelos regulamentos que devem, necessariamente, aplicar fielmente aquelas normas.

A economia em razão de sua mutabilidade, propiciou o aparecimento de muitos outros mecanismos mais rápidos que os Estados utilizam constantemente para controlar os fatos econômicos ou 
3. Ordnung der Wirtschaft als geschichtliche Aufgabe und rechtsschöpferische Leistung 1937, p. 54. Ver especialmente Ludwig Raiser, Wirtschaftverfassung als Rechtsprobleme em: Die Aufgabe des Privatrechts, Athenäum Verlag, 1976, p. 22-37. Quanto a situação atual da teoria neo-liberal na Alemanha, ver também Fritz Rittner, Zum gegenwärtigen Stand neolieraler Rechtstheoria, em: Archiv für die civilistiche Praxis, n? 180 (1980) p. 392-402. Nesse ensaio Rittner analisa o trabalho de Mestmäcker, Recht un ökonomisches Gesetz.

4. Economic analysis of law, Boston, 1972, p. 1. Ver tambémo ensaio The rights of creditor or affiliated corporations, Law Review University of Chicago, 43 (1975) p. $142 \mathrm{ff}$ e seguintes. No entanto Posner (Economic analysis. p. 4). reconhece, por exemplo, que o "economista não pode nos dizer se é justa a distribuição existente da renda e da riqueza", o que representa a total exclusão do critério de justiça. No que se refere à situação atual na Alemanha, onde a 'área de direito' é de grande importância, ver Maximilain Fuchs, 'Die Behandlung von Ehe und scheidung in der' ökomischen Analyse des Rechts, FamRZ 26 (1979) p. 533-557. dirigí-los nesta ou naquela direção. A posição do Estado moderno não é neutra na medida em que considera o mercado um processo. Mesmo que seu núcleo não deva ser objeto de regulamentação definida ou permanente, o Estado estabelece as condições preliminares, ou pré-condições ao desenvolvimento deste mesmo mercado. Por vezes o Estado faz isto diretamente embora por etapas e períodos limitados. Os limites desta regulamentação são delineados na constituição (uma constituição econômica formal) e pela legislação ordinária que dá maior ou menor margem de liberdade ao Estado para gerir os fatos econômicos.

Além disso, a 'constituição formal' da economia não consiste, como escreveu Franz Böhm³ ${ }^{3}$, em um grupo de fatos econômicos mas sim num sistema de normas com o escopo de ordenar o interrelacionamento das forças econômicas.

Na lei brasileira, foi a Constituição de 16 de julho de 1934 que, pela primeira vez, regulou a 'Ordem Econômica e Social' e ressaltou que a economia era governada pela Justiça, declarando, em seu art. 115, que "a ordem econômica deve ser organizada respeitando os princípios da justiça e as necessidades da vida nacional, com dignidade." Mais adiante começa a disciplinar, em todos seus aspectos, a 'constituição formal da economia' num sentido nacionalista (especialmente nos arts. $117,118, \S 4^{\circ}$.) com um enfoque trabalhista (art. 121), com o aperfeiçoamento da economia popular, criando um tribunal especial para os trabalhadores (art. 122), e permitindo uma profunda interferência do Estado na economia. Estes princípios subsistiram, em geral, nas Constituições de 1946 (art. 145 e seguintes) e de 1967 (art. 157 e seguintes) e na Emenda Constitucional n. 1 de 17 de outubro de 1969 (art. 160) emoldurando um modelo misto de constituição, com um mercado livre, pelo menos em princípio e uma legislação previdenciária ainda mais importante.

\section{A Insuficiência de uma interpretação puramente econômica do direito}

No tocante à crescente importância da economia em relação ao direito existe um número considerável de autores que acreditam poder construir uma interpretação econômica do direito; em vez de critérios de justo ou injusto, temos soluções que são mais úteis ou menos úteis às partes interessadas. Esta escola de pensamento, que tem alcançado intensa repercussão no mundo inteiro, quase sempre leva em consideração os custos, econômico e social das medidas governamentais. Mais do que isto, ela sempre submete a ação do Estado e dos particulares, em todos seus aspectos, ao critério da utilidade e da otimização dos recursos disponíveis, ou as apresenta como objeto de uma opção baseada nas mesmas regras. E interessante notar que a teoria de Posner se fundamenta no fato de que "está implícito na definição do homem como um maximizador racional do seu interesse próprio que as pessoas reagem a

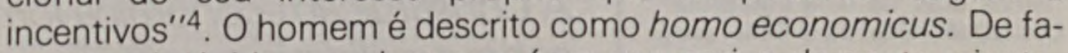
to, não há dúvida que o interesse é um expressivo elemento orientador do comportamento humano, e que, entre os muitos estímulos 
5. H. Schelski (Die Soziologen und das Recht, in Rechtstheorie, n: 9 (1978) p. 1-21) estudou criticamente a sociologia alemã mais recente e assinalou que Arnold Gehlen, Ralph Dahrendorf, Habermas e Luhmann em suas teorias, não levaram em conta o conceito de Direito. O mesmo poderiamos dizer de uma interpretação econômica do Direito porque, neste caso, se temos observado os fatos, teríamos uma economia legal sem Direito. que uma pessoa pode receber, o econômico é dos mais importantes.

Mesmo o direito de família - que hoje, como sempre atribui importância à aplicação de critérios éticos - estará igualmente sujeito à regra da utilidade.

Todos certamente sabem da existência das duas relações domésticas fundamentais que nos permitem dividir o direito de família em pessoal e patrimonial. No entanto, mesmo no direito patrimo- " nial, existem certos aspectos éticos. Não é possível afirmar que as ações das partes em um matrimônio ou na dissolução de um matrimônio são sempre motivadas por aspectos econômicos. Por outra parte, todos têm consciência da 'base econômica' do direito de família, que se cristaliza na obrigação da indenização e na propriedade conjugal e sabem ainda, que a obrigatoriedade do pagamento da pensão, que é recíproca, é de importância fundamental para a existência do matrimônio. Esta afirmação não exclui a 'base ética' ou 'base pessoal', igualmente necessária para a existência da família. É bem verdade que os critérios da utilidade e do lucro estão presentes no próprio nascimento de uma disciplina: o direito comercial. Não podemos, no entanto, tomar a parte pelo todo, e considerar o critério da utilidade, elemento importante para certos ramos do direito, como válido para uma interpretação predominante ou puramente econômica de todo o direito. Como se pode ver, esta teoria econômica não resolve o problema jurídico e nem mesmo o problema de um inter-relacionamento entre a ordem jurídica e a economia, uma vez que ela apenas ressalta a racionalização econômica que é a interpretáção econômica da ordem jurídica.

Apesar da relevância que autores modernos atribuem a esta teoria e mesmo quando ela leva em consideração outros fatores, podemos concluir que o predomínio da economia tem sido exagerado e, conseqüentemente, submete o direito a uma racionalização que não lhe é própria. Quando o direito é submetido a um modelo hermenêutico diverso - por exemplo, o modelo das ciências naturais - determinadas conclusões são, por certo, muito interessantes, no conjunto, o fenômeno jurídico fica degradado, perdendo sua importância. Aqueles autores que embora competentes em direito, descartam a justiça ou recusam o conceito legal cometem o mesmo equívoco. Não pensem, no entanto, que a idéia de repudiar este conceito não seja freqüente em outros campos da ciência. Existem sociólogos que, escrevendo sobre a sociologia do direito, transformam o direito em mero mecanismo de regulamentação social, despido de qualquer valor que não resulte diretamente do modelo efetivamente adotado ${ }^{5}$. Tal perspectiva de análise, quer diga respeito à otimização ou à utilidade de soluções jurídicas, como fator predominante na atividade dos indivíduos ou do Estado, não merece ser apoiado em sua inteireza.

\section{A Constituição econômica formal e sua projeção sobre a realidade econômica}

Descartada uma concepção econômica do direito pelo seu as- 
6. Gerd Rinck. Wirtschaftsrecht, Köln, 1977, p. 18, ff.

7. Grundsätze der Wirtschaftspolitik, Tübingen, 1959, p. 153 e segs. pecto unilateral, embora seja evidente que a economia, entre muitos outros fatores tenha grande importância, seria conveniente examinar os elementos das normas econômicas que orientam a economia em determinado país. A constituição econômica formal é o conjunto de princípios constitucionais que determinam e comandam os fatos econômicos, ou seja, toda a ideologia econômica posta em prática.

A luz do 'princípio da não-identificação' é possível que não fizesse sentido aceitar uma ideologia definida na própria constituição; não o fazendo, porém, poderia dizer-se que fora adotado um sistema econômico absolutamente liberal. Talvez para evitar este risco, algumas constituições - não todas - delineam o tipo de normas econômicas adotadas. Em países totalitários, que são marcadamente ideológicos, a 'identificação' é da própria natureza do sistema e se manifesta, acima de tudo na 'constituição econômica formal'. Por esse motivo, ela não é considerada uma solução democrática, pelo menos do tipo liberal (existirá algum outro tipo de democracia?) e terminará por estabelecer a ditadura na medida em que qualquer ideologia - em especial uma de caráter pluralista - escapará ao controle constitucional.

Sabe-se que a inclusão de uma doutrina socialista na constituicão levaria, se a constituição fosse inflexivel nesse aspecto, a que todos os partidos se tornassem socialistas ou então que aqueles com orientação diversa a ela fizesse oposição. Deveria, portanto, haver harmonia entre política e economia na medida em que cada tipo de Estado determina ou tende a determinar um modelo específico da 'constituição econômica formal'. Mas a tendência, pelo menos em países pluripartidários, favorece um sistema flexivel que se adapte progressivamente às mudanças da economia, sem representar aplicação sistemática de uma ideologia. Discutiu-se sobre a correção de dizer-se 'constituição econômica'. Se identificamos Estado com sociedade deveríamos falar da constituição apenas como Constituição do Estado. Mas achamos aceitável a expressão 'constituição econômica', de vez que foi o próprio Estado quem 'abriu uma brecha' que nos permite constatar que a Constituição tem um capítulo econômico ${ }^{6}$. Podemos afirmar, em outras palavras que o modelo da constituição é, até certo ponto, auto-indicativo. Levando em conta a generalidade das normas, resulta evidente de sua aplicação que o point de appui muda, sustentado por um ou outro dos princípios inerentes ao modelo, de vez que estes não são contraditórios mas apenas complementares.

\section{A Influência da escola neo-liberal e da escola social e sua projeção sobre a ordem juridica} Eucken ${ }^{7}$.

O pensamento neo-liberal se relaciona com a escola de Walter

Esta afirma que não podem existir soluções intermediárias ou mistas em matéria de economia, uma vez que tudo é proposto como alternativa; ou uma economia centralmente planejada ou uma economia competitiva. Daí não aceitar como solução adequada, por 
8. Keynes, Das Ende des LaissezFaire, 1916, p. 31 e segs.

9. Condition of the working class in England, capítulo VII, que analisa a situação dos trabalhadores em 1800; esta análise pode ser feita em muitos países, por exemplo, na Polônia. Ver Lucjan Blit, The origins of Polish Socialism, Londres, 1971, p. 5 e segs.

10. Esta tensão é caracterizada como a "dialética da complementariedade" no sentido assinalado por Miguel Reale em magnífico livro (Experiência e Cultura, São Paulo, 1977, p. 162 e segs), isto é, como uma 'dialética aberta' que não pode ser reduzida a uma 'dialética fechada', seja ela hegeliana ou marxista. Conseqüentemente, temos um 'modelo dinâmico'. econômico, em que os aspectos liberal e social são reciprocamente considerados de tal forma que. em determinado momento, um ou outro desses elementos é o predominante.

11. O 'Promotor State' age de modo tão diversificado que quando o GATT tentou classificar os diferentes tipos de grants-in-aide teve que abandonar a idéia de fazê-lo segundo os seus objetivos (Ver D. Scheuing, Les Aides Finacières Publiques, Paris, 1974, p. 49 , nota 87 ). exemplo, a posição keynesiana que afirma que "a medida ideal para a organização e controle da economia deve ser procurada num ponto intermediário entre o indivíduo e o estado moderno"8. De acordo com Keynes, a questão não pode ser colocada de forma alternativa, pelo contrário, a solução para os problemas de organização da economia não estará no Estado nem no indivíduo, mas em algum ponto intermediário. O capitalismo clássico é a origem de tudo.

$O$ velho espírito capitalista é bem descrito na passagem em que F. Engels examina a situação dos trabalhadores na Inglaterra9: "Um dia eu fui a Manchester acompanhado de um senhor de classe média. Mencionei-lhe as degradantes e insalubres favelas e chamei sua atenção para as condições revoltantes da parte da cidade em que viviam os operários das fábricas. Disse-Ihe que em toda minha vida nunca vira cidade tão mal construída. Ele me ouviu pacientemente e, numa esquina da rua em que nos separamos comentou: E no entanto ganha-se muito dinheiro aqui. Bom dia, meu senhor".

Esta situação não existe mais pois várias idéias sociais se implantaram no sistema capitalista, caracterizando-o como um modelo misto, com idéias liberais e alguns princípios socialistas em permanente estado de tensão ${ }^{10}$. Trata-se de um modelo flexível, no qual razões econômicas e de justiça se combinam para resolver situações e provocar iniciativas do Estado e do indivíduo.

Como vimos, a escola neo-liberal se inclina por uma solução radical do problema, no sentido de que uma 'ordem econômica livre' deve prevalecer, limitando a intervenção estatal, no que tange a atividade econômica, a um papel pequeno. É evidente que esta teoria se opõe com veemência à formação de monopólios e portanto favorece a reivindicação de uma legislação antimonopolista. Em geral, porém, o papel do Estado é consideravelmente reduzido e, ao identificar a solução numa alternativa radical entre a economia centralizada ou de mercado, coloca os modelos mistos completamente fora de cogitações. O problema é saber se é dever do Estado regular ativamente a economia e até que ponto deve chegar. Em um modelo misto, todos os aspectos ativos do Estado não podem ser descritos a priori uma vez que ele opera de muitas formas diferentes, dependendo da situação econômica de cada país ${ }^{11}$. Talvez, por isso, seja difícil explicar sistematicamente um modelo econômico misto. A intervenção do Estado é muito mais ampla do que a simples organização de medidas para coibir monopólios ou práticas monopolistas. Nos modelos mistos uma grande parte da indução do mercado cabe também ao Estado.

Um modelo misto é, portanto, um modelo que contém elementos neo-liberais mas, que vai além, exigindo um papel mais ativo do Estado. Nesse sistema, o Estado não só garante a organização do mercado como também opera ativamente, com capacidade de elaborar planos de construção, indireta ou mesmo direta, desse mesmo mercado.

O progressivo e constante aumiento da intervenção estatal pode, com o tempo, dar cabo do sistema econômico de mercado e eis por que se faz necessário que a Constituição estabeleça seus limites. 
12. Unger, The Totalitarian party, Londres, 1974, p. 16 e segs. Este estudo é interessante porque nos trás as semelhanças e identidades entre o nacionalsocialismo e o comunismo com ênfase nos aspectos da disciplina. A respeito deste tema, $L$ individualisme et le droit de Marcel Waline, Paris, 1949, especialmente p. 55 e segs. é ainda um clássico. No tocante à origem medieval da 'disciplina ideológica', manifesta na expressão "Discentes, id est, Laici", ver Walter Ulmann, The individual and society in the middle ages, Baltimore, 1966, especialmente p. 17 e segs. : e Principals of government and politics in the middle ages, Londres, 1966, p. 67 e segs.

13. Ver nosso estudo, A Fundamentação jurldica do mercado de capitais, Porto Alegre, 1973, p. 16 e segs. A correção monetária expandiu-se extraordinariamente depois de 1964. A lei n? 4.937 (1964) aplicou-a aos créditos da União. Em 1966, o Decreto n? 58.400 determinou sua aplicação aos créditos do Imposto de Renda. No que concerne o mercado de capitais, a correção monetária foi aplicada a várias operações pela Lei n? 4.728 , de 1965 , arts. $26 ; 27, I ; 28 ; 29$, IV; Res. n: 18, de 1966: e Decreto-Lei n? 403, de 1968 , art. $3^{\circ} \S 2{ }^{\circ}$ e em muitas outras hipóteses. O problema da inflação começa agora a motivar estudos em todo o mundo, inclusive nos Estados Unidos. Ver Keith S. Rosenn, Protecting contracts form inflation, the business lawyer, n: 33, 22 (1978) p. 729 e segs.

14. No tocante aos contratos cogentes, ver o estudo de San Tiago Dantas, Problemas do direito positivo, Rio, 1953, p. 13 e segs.

15. Contratos cogentes continuaram em evidência depois de 1964 mas os incentivos ao ctédito
Esses limites são determinados, em parte pelos direitos e garantias individuais. Uma garantia, por exemplo, da propriedade e conseqüentemente dos direitos subjetivos contra qualquer tipo de expropriação na qual o valor justo e corrente do bem expropriado não seja pago. Já vimos que o socialismo e capitalismo se apresentam com matizes pois que não há mais oposição radical entre os dois sistemas na medida em que toda ordem econômica é ou tende a ser mista. No entanto, o sistema capitalista tem maiores possibilidades de evoluir na direção de uma concepção mais social do próprio capitalismo do que um sistema socialista no sentido de uma concepção mais capitalista de seu modelo social. Esta afirmação é verdadeira enquanto for possivel dizer-se que, mesmo num sistema político forte, o fundamental não é tanto a discussão dos próprios dogmas mas sim a existência de seguidores fiéis das ordens do partido ${ }^{12}$.

A organização começa a ficar mais importante do que sua própria ideologia. A afirmação é feita cum grano salis. Em síntese, considerando os elementos já mencionados da própria Constituição: a importância atribuída à propriedade, de uma parte, e a amplamente admitida intervenção do Estado no domínio econômico da outra; as garantias aos trabalhadores; finalmente, o vasto sistema social, a organização econômica brasileira tem que ser classificada como um modelo misto.

\section{O Modelo econômico brasileiro}

Nosso modelo, como já foi explicado, é de natureza mista, na medida em que procura combinar uma economia de mercado com os princípios e instituições de uma ordem social. Dado seu caráter geral, não basta examinar as disposições constitucionais para se ter uma noção exata da realidade. Paralela à 'constituição econômica formal' existe uma lei criada pela própria economia que resulta de usos e costumes, de instrumentos práticos e de modos de operacão. Neste particular, a economia brasileira criou seu próprio modelo abrangendo os mais diversos setores. De um lado, estabeleceu um amplo planejamento indutivo, de outro, fixou uma correção monetária (indexação) sem a qual a existência de um incipiente mercado de capitais não seria possível ${ }^{13}$. Foi uma concepção econômica de taxação que permitiu o estabelecimento de um amplo sistema de incentivos ao crédito, recorrendo à idéia desenvolvida por Posner de que a tendência das pessoas é maximizar seus próprios interesses.

Vale notar que estes incentivos ao crédito começaram a aparecer com maior dimensão na história econômica do Brasil depois de 1964. Antes daquela data o instrumento fundamental para o desenvolvimento econômico não era planejamento indutivo resultante dos referidos incentivos (cogência ex-vita) mas sim os 'contratos cogentes' (cogência ex-lege) embora isso não fosse bem conhecido $^{14}$. A questão da constitucionalidade dos chamados 'empréstimos compulsórios' ficou famosa e chamou a atenção para o problema ${ }^{15}$. Posteriormente vieram os incentivos e as principais áreas cobertas foram no plano nacional, o turismo, o florestamento, o reflorestamento e a pesca e ainda investimentos no Nordeste e na 
se tornaram mais comuns como técnica de subsídio. No entanto, os seguintes contratos cogentes, entre outros, podem ser citados na lei brasileira quando sua constitucionalidade foi debatida (RMS 11.252 Esteves e Irmãos S.A. vs. Estado do Paraná; RDA 80/172; Súmula 418; hoje a matéria é regulada pela Emenda Constitucional $n^{\circ} 1$, art. $22 \S 2^{\circ}$ ) a venda obrigatória de café ao I.B.C., o contrato cogente do seguro contra acidentes de trabalho, a compra obrigatória de ações da PETROBRAS, a venda obrigatória de cambiais de exportação; os depósitos obrigatórios de fundos dos bancos privados no Banco do Brasil, etc. Ver nosso ensaio - A Natureza jurídica dos contratos cogentes e dos incentivos fiscais, na Revista Jurldica n: 118, Rio, 1972. p. 52 e seguintes.

16. Decreto-Lei n: $1376 / 74$, art $1,2,3$, e segs.

17. Ver Decreto-Lei $n$ ? 157, art. 3: Decreto-Lei n: 1214/72; Decreto-Lei n? $1338 / 74$ art. $3^{\circ}$.

18. Um dos aspectos importantes foi a aplicação da correção monetária aos balanços das empresas, criando assim uma técnica original brasileira (Lei n? 6.404, de $15 / 2 / 76$, art. 185 etcl que começou a chamar a atenção de especialistas estrangeiros (Ver Tassilo Ernst, Das neue brasilianische Aktiengesetz, A. G. 1977, p. $275 \mathrm{ff})$.

19. Message from the President of the United States relativo ao nosso sistema tributário federal, Abril, 20, 1961, 87․ Congresso, Primeira Sessão (1961).

20. Cristoph Bellstedt, Die Steur als Instrument der Politik, Berlim, 1966 , p. 336 e segs. Neste importante estudo o autor compara os sistemas alemão e americano de incentivos ao crédito.

21. O Supremo Tribunal Federal decidiu neste sentido no caso da Cia. Miribo de Mineração vs. Geo Mineração S/A, na RTJ 91 (1980), p. 1167 e segs. bem como em outros casos.
Amazônia ${ }^{16}$. Fez-se uma tentativa de dinamizar o mercado de capitais, por meio do Decreto-Lei n? 157, de 10 de fevereiro de 1967 e de diversas outras disposições. O referido Decreto-Lei autorizava, no seu art. $2^{\circ}$, posteriormente modificado, que instituições financeiras vendessem certificados de compra de ações ${ }^{17}$. Um dos objetivos era transformar corporações fechadas em empresas de capital aberto, uma vez que só eram compradas ações de empresas que tivessem se comprometido a colocar no mercado parcela substancial dos títulos resultantes dos aumentos de capital. No entanto, nada seria possível se não existisse estabilidade monetária. A correção monetária foi progressivamente introduzida em determinados setores como forma de superar os problemas resultantes da inflação ${ }^{18}$. Foi aplicada setorialmente, nos termos das disposições legais específicas, de forma a se constituir em importante elemento de canalização da poupança para o setor que o governo desejava dinamizar. Assim, criou-se no país uma economia com duas moedas; uma nominal, outra real.

Quando se compara os vários ramos do direito, é sem dúvida, na concepção econômica dos impostos que o pensamento de Posner marca sua presença. Este mesmo raciocínio levou o Governo dos Estados Unidos, em 1961, a reformular a economia americana. Foi enviada uma mensagem ao Congresso ${ }^{19}$, propondo um considerável abatimeno fiscal em benefício das empresas, principalmente para a renovação de seu equipamento. O Congresso rejeitou a proposta e estranhamente, especialistas de grande reputação à época, como os professores Dan Troop Smith e Hogan, bem como as associações comerciais mais poderosas, se opuseram à medida. $\mathrm{O}$ abatimento fiscal em larga escala, aparentemente, favoreceria cerca de $85 \%$ dos negócios americanos ${ }^{20}$. Não se pode afirmar que estas idéias, no início dos anos sessenta, tenham inspirado a criação de um amplo sistema de incentivos pelos legisladores brasileiros. A idéia específica na economia brasileira não é um planejamento indutivo baseado em benefícios fiscais nem a adoção do 'valorismo' (correção monetária) em determinados setores mas uma combinação de ambos. Disso resultou um sistema de 'duas moedas', que usa o meio circulante como um dos elementos de maior peso para orientar a poupança nacional. Esta foi a solução econômica: teria sido um solução justa?

Nos negócios entre indivíduos, fora da esfera delimitada pela legislação, o princípio vigente sempre foi o nominalismo, em que o mingüante poder de compra da moeda não é levado em consideração. Desta forma, o credor perderia muito nas transações; até que a jurisprudência começou a afastar-se do princípio de que não haveria correção monetária sem lei que a estabelecesse. Neste particular, o primeiro passo foi a determinação que a indenização por prejuízos teria que ser calculada com correção monetária sobre a importância devida. No entanto, danos por inadimplência de contrato relativo a divida pecuniária estariam sujeitos ao 'nominalismo', ou seja, não sofreriam correção monetária. Mais tarde os tribunais resolveram 'modificar' este entendimento e determinaram que a quantia devida fosse corrigida a título indenizatório ${ }^{21}$. Recentemente foi promulga- 
22. Lei $n^{\circ} 6.899$ de 8 de abril de 1981 , arts. $1^{\circ}$ e 2 . da lei instituindo a correção monetária compulsória em demandas judiciais, em consonância, portanto com a jurisprudência. ${ }^{22}$.

Tomando em conjunto os pensamentos econômico e jurídico, podemos concluir que o segundo prevaleceu sobre o primeiro, de vez que a solução justa é, na maioria dos casos muito mais importante do que meramente útil. 
